\title{
Experimental Study of Scouring Characteristic Around Hexagonal Artificial Reef
}

\author{
Haryo Dwito Armono ${ }^{1, *}$ and Harish Wirayuhanto ${ }^{2}$ \\ ${ }^{1}$ Associate Professor, Ocean Engineering Department, Faculty of Marine Technology, Institut \\ Teknologi Sepuluh Nopember, Surabaya, Indonesia \\ ${ }^{2}$ Graduate Student, Ocean Engineering Department, Faculty of Marine Technology, Institut \\ Teknologi Sepuluh Nopember, Surabaya, Indonesia
}

\begin{abstract}
Artificial reef is a structure placed underwater which has similar function with natural reef. Artificial reef can also serve as a submerged breakwater. When placed in shallow water, the structure is vulnerable to scouring and soil subsidence which cause structural failure. This paper present serial testings in Ocean Environment and Ocean Energy Laboratory, Ocean Engineering Department, ITS, to determine the scouring characteristic with variation of gap, and waves for 1: 10 model scale hexagonal artificial reef. The results of this research can guide the planning of structural protection against scouring. From a series of tests, it can be summarized that for 1 diameter gap reef distance, the maximum scouring occurs behind the structure, whereas for no gap distance, it occurs at the front of the structure. At the center of the structure, for no gap distance, sedimentation occurs dominantly, whereas for 1 diameter gap distance, scouring process occurs dominantly. The maximum scouring depth $(5,3 \mathrm{~cm})$ occurs when the gap is equal to 1 diameter of reefs and minimum $\operatorname{scour}(2,9 \mathrm{~cm})$ occurs when there is no gap between the reef.
\end{abstract}

\section{Introduction}

The damage of coral reefs affects the lives of many kinds of marine organisms, especially in tropical waters where the marine productscould decline severely due to low productivity of coral reefs. Coral reef recondition needs to be taken to restore function and productivities. One effort that can be done to restore the condition of coral reefs is to transplant coral on artificial reefs. Artificial reef are objects or structures placed on the sea floor that expected to resemble the characteristics natural coral reef. This structure is used to provide a sanctuary for marine animals and serves as a submerged breakwater that reduces wave energy came before the shoreline [1]. There are several types of artificial reefs that have been developed, such as Aqua Reef, Turtle Reef, Reef Ball, Ultra Ball, Bay Ball, Square Reef and Reef Bottle. In this study, the new reef model is developed in the form of hexagon called Hexareef.

Any submerged breakwater, or in this case Hexareef and other types of structures when placed on a marine environment with a dynamic water flow, will lead to changes in water flow field, thus forming a vortex flow around the structures that cause scouring $[2,3]$. If the structure scouring occurs continuously, the foundation is unstable,and lead

\footnotetext{
*Corresponding author :armono@oe.its.ac.id
} 
to structural failure. Failure of structures include overturning, settling, and sliding[4].Scouring due to wave caused by the difference of hydostatic pressure on the ocean floor following the fluctuation of surface waves. Hydrostatic pressure is transmitted to the seabed and formed a huge difference in the vertical and horizontal pressure that causes soil liquefaction and scouring at the seabed [5,6]. The shape of the struture affect the current flow and waves that cause scouring. The depth of scouring that occurs around the square and hexagonal structure with the placement of wave direction different is greater than the depth of scouring around the cylindrical structure $[5]$.

Furthermore, scouring depth will affect some of the factors that cause changes in water conditions including wave height, wave period, water depth, and the type of waves generated $[7,8]$. These factors are summarizedintoanon-dimensional parameter that contains the independent variables in testing of the characteristics of scouring nearHexareef. These parameters include the number Keulegan Carpenter (KC) and mobility parameters on the seabed $(\Psi)[7,9]$.

In this research, the pattern and characteristics of scouring that occurs in near Hexareef model affected by some wave parameters and variation of distance (gap) between Hexareef during test will be examined. The maximum and minimum scour will be noted, for Hexareef placement with and withoud gap. Fig. 1shows typical shape and arrangement of Hexareef during test.
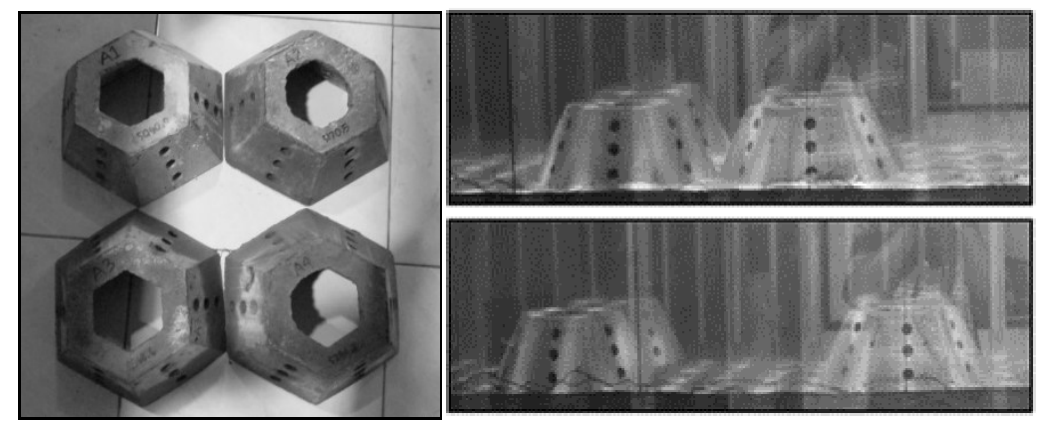

Fig. 1. Hexagonal Artificial Reef Structures (Hexareef) Placement in the Wave Flume

\section{Material and Methods}

\subsection{Testing Preparation}

Physical model testing performed in the wave tank located on Laboratory of Marine Environmental and Marine Energy, Department of Ocean Engineering, Institut Teknologi Sepulluh Nopember (ITS) Surabaya. The installed wave generator has the capability of generating regular and irregular waves with various wave spectrums. The length of the wave tank is $24 \mathrm{~m}$ with the height and width of $2 \mathrm{~m}$. The model placed in the middle of the wave tank, on top of $35 \mathrm{~cm}$ sand layer with the front slope of 1:7. The model were submerged on $65 \mathrm{~cm}$ of water level. The tests performed for hexagonal reef with gap distance and variation period and wave height. 
Due to limitation of quantity, only 2-layer Hexareef model arranged laterally will be tested.Therefore,a partition wall was installed in the middle of wave tank and only $57 \mathrm{~cm}$ of wave tank used for the test. Figure 2 shows the arrangements of the models and wave probe placement in the wave tank during test.

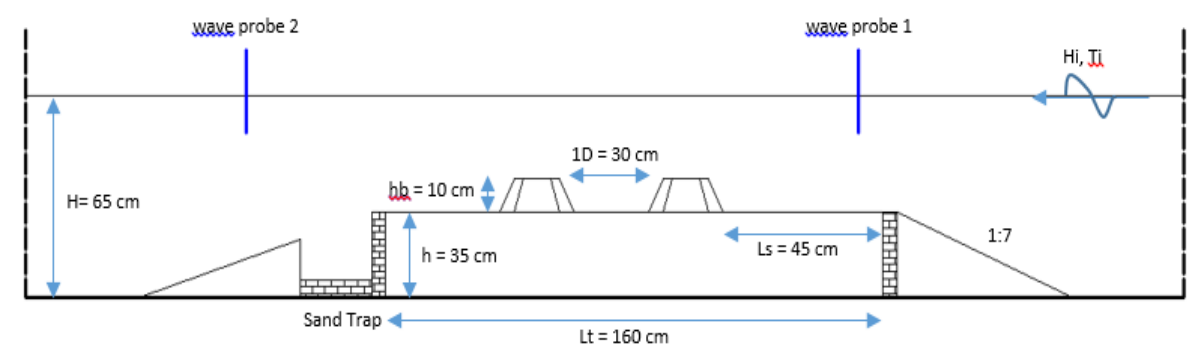

a. side view

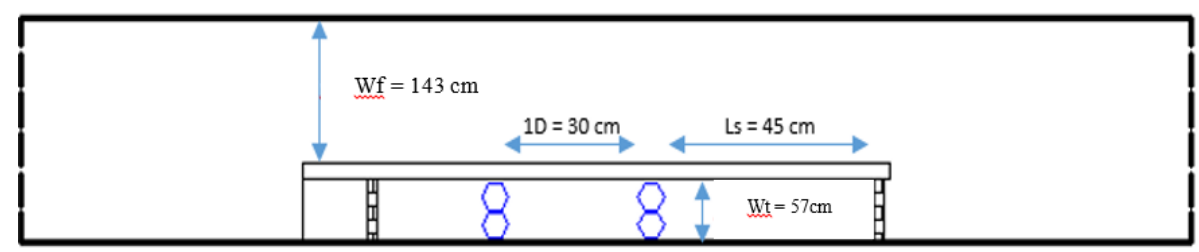

b. top view

Fig. 2. Testing plan in the wave flume

The models were made of concrete with the scale on 1: 10 to the prototype. With the height of $10 \mathrm{~cm}$, the width of model was $18,5 \mathrm{~cm}$ at the top and $25 \mathrm{~cm}$ at the base The Hexareef models were placed in the sand layer with average diameter ( $\left.D_{50}\right)$ of 0.28 $\mathrm{mm}$ and density of $2650 \mathrm{~kg} / \mathrm{m}^{3}$. The thickness of sand layer was $35 \mathrm{~cm}$. The experiment will compare the scour between structure arrangement with 1 diameter (1D) to the structure without gap (0D).

Table 1.Number of Test, Wave properties, and Structure configuration

\begin{tabular}{|c|c|c|c|}
\hline \multicolumn{5}{|c|}{ Regular Wave } \\
\hline $\begin{array}{c}\text { No. } \\
\text { Test }\end{array}$ & $\begin{array}{c}\text { Ti } \\
{[\mathbf{s e c}]}\end{array}$ & $\begin{array}{c}\text { Hi } \\
{[\mathbf{m}]}\end{array}$ & Gap \\
\hline 1 & 1 & 0,1 & 0D \\
\hline 2 & 1 & 0,2 & 0D \\
\hline 3 & 2 & 0,1 & 0D \\
\hline 4 & 2 & 0,2 & 0D \\
\hline 5 & 1 & 0,1 & $1 \mathrm{D}$ \\
\hline 6 & 1 & 0,2 & $1 \mathrm{D}$ \\
\hline 7 & 2 & 0,1 & $1 \mathrm{D}$ \\
\hline 8 & 2 & 0,2 & $1 \mathrm{D}$ \\
\hline
\end{tabular}

\begin{tabular}{|c|c|c|c|}
\hline \multicolumn{4}{|c|}{$\begin{array}{c}\text { Irregular Wave } \\
\text { JONSWAP) }\end{array}$} \\
\hline $\begin{array}{c}\text { No. } \\
\text { Test }\end{array}$ & $\begin{array}{c}\text { Ti } \\
{[\mathbf{s e c}]}\end{array}$ & $\begin{array}{c}\text { Hi } \\
{[\mathbf{m}]}\end{array}$ & Gap \\
\hline 9 & 1 & 0,03 & 0D \\
\hline 10 & 1 & 0,05 & $0 \mathrm{D}$ \\
\hline 11 & 1 & 0,07 & 0D \\
\hline 12 & 1 & 0,03 & $1 \mathrm{D}$ \\
\hline 13 & 1 & 0,05 & $1 \mathrm{D}$ \\
\hline 14 & 1 & 0,07 & $1 \mathrm{D}$ \\
\hline
\end{tabular}

A series of reguler and irregular wave based on JONSWAP spectrum will be applied to Hexareef model as listed in Tabel 1. During tests, the variation not only made for wave height and period, but also distance (gap) between the structures. Initially the surface of 
sand was smoothed and levelled. The waves were generated for 20 minutes for each test. Every 5 minutes the waves generator were stopped, and the pattern on the sand surface were mapped and measured using laser distance meter.

\subsection{Data Acquisition}

A probe is installed in the front of the model to record the incoming waves. Another probes were placed behind the model to record the transmitted waves. The comparison of incoming and transmitted waves will not be discussed in this paper. However, the transmission coefficients were similar to other test of artificial reefs [1]. The fluctuation of water level recorded by the probes were analyzed to estimate the significant wave height and period.Callibration of each probes were made before the test to ensure the correct recording of water level fluctuation. Only maximum and minimum scour were noted for the whole test.

The pattern of depth of scour in the vicinity of the Hexareef model were measured and mapped every 5 minutes using laser distance meter. A map of sand contour before and after test were made every 20 minutes to estimate the maximum depth of scour and its location. A non-dimensional parameter will be developped to evaluate the influence of gap and wave characteristics to the depth and location of scour. Two locations will be examined during the test; in the front and rear of Hexareef models.

\section{Result and Discussion}

\subsection{Waves Data}

For every test performed, the water fluctuation level in the front probe will be recorded on Channel 1, while the water level fluctuation in the rear of the model were recorded on Channel 2. The recording data in this channel will be evaluated for its signficant wave height and period for each test and listed in Tabel 2.

Table 2.Generated Wave Height and Period for Each Test.

\begin{tabular}{|c|c|c|c|c|}
\hline \multicolumn{5}{|c|}{ Regular Wave } \\
\hline \multirow{2}{*}{$\begin{array}{c}\text { No. } \\
\text { Test }\end{array}$} & \multicolumn{2}{|c|}{ Ch1(Front) } & \multicolumn{2}{c|}{ Ch2 (Rear) } \\
\cline { 2 - 5 } & $\begin{array}{c}\text { Hm } \\
{[\mathbf{c m}]}\end{array}$ & $\begin{array}{c}\text { T } \\
{[\mathbf{s e c}]}\end{array}$ & $\begin{array}{c}\text { Hm } \\
{[\mathbf{c m}]}\end{array}$ & $\begin{array}{c}\text { T } \\
{[\mathbf{s e c}]}\end{array}$ \\
\hline 1 & 8,3 & 2,0 & 12,1 & 2,0 \\
\hline 2 & 17,2 & 2,0 & 23,1 & 2,0 \\
\hline 3 & 11,4 & 4,0 & 11,1 & 4,0 \\
\hline 4 & 17,3 & 4,0 & 21,8 & 4,0 \\
\hline 5 & 9,7 & 2,0 & 12,7 & 2,0 \\
\hline 6 & 19,5 & 2,0 & 23,5 & 2,0 \\
\hline 7 & 11,3 & 4,0 & 10,5 & 4,0 \\
\hline 8 & 18,2 & 4,0 & 21,7 & 4,0 \\
\hline
\end{tabular}

\begin{tabular}{|c|c|c|c|c|}
\hline \multicolumn{5}{|c|}{$\begin{array}{l}\text { Irregular Wave } \\
\text { JONSWAP) }\end{array}$} \\
\hline \multirow{2}{*}{$\begin{array}{l}\text { No. } \\
\text { Test }\end{array}$} & \multicolumn{2}{|c|}{ Ch1(Front) } & \multicolumn{2}{|c|}{ Ch2 (Rear) } \\
\hline & $\begin{array}{c}\mathrm{Hm} \\
{[\mathrm{cm}]}\end{array}$ & $\begin{array}{c}\mathrm{T} \\
{[\mathrm{sec}]}\end{array}$ & $\begin{array}{l}\mathrm{Hm} \\
{[\mathrm{cm}]}\end{array}$ & $\begin{array}{c}T \\
{[\mathrm{sec}]}\end{array}$ \\
\hline 9 & 6,1 & 2,2 & 6,9 & 2,2 \\
\hline 10 & $\overline{9,0}$ & 2,2 & 10,0 & 2,1 \\
\hline 11 & 11,2 & 2,2 & 12,9 & 2,2 \\
\hline 12 & 6,0 & 1,9 & 6,9 & 2,2 \\
\hline 13 & 8,9 & 2,1 & 10,4 & 2,2 \\
\hline 14 & 10,7 & 2,0 & 12,5 & 2,1 \\
\hline
\end{tabular}




\subsection{Scouring on Regular Waves Test}

For the tests with similar wave height (Test 2 and Test 4), it was found that the larger the wave period, the greater the scouring that occurs in the structure. While test using wave with the same period (Test 3 and Test 4), the greater the incoming wave height, the greater the scouring that occurs.Based on experiments for regular wave above, for experiment without gap (0D), the biggest scour observed during Test $4(17.3 \mathrm{~cm}$ wave height and wave period of 4 seconds). The elevation of sand layers changed gradually and undergoing expansion on the front and rear of the structure. In the end of test without gap, its observed that the front left of the model suffered sedimentation while scouring occurs in the back side of the model. At the center of the structure there was small sedimentation, but in certain parts experiencing scouring.

When the gap introduced in the model, most of the area suffer scouring. Small sedimentation and scour were observed inthe gap between structures. Overall, the depth of scour in the model with gap is bigger than model without gap. The maximum depth observed at Test 8 (18.2 cm wave height and wave period 4 seconds).Similar pattern to model with gap were found, that the larger the wave period, the greater the scouring that occurs in the surrounding area of the structure. While on wave with the same period (Test 7 and Test 8), the greater the incoming wave height, the greater the scouring that occurs. Due to limited space in this paper, the scouring patterns are not presented.

\subsection{Scouring on Irregular Waves Test}

During experiments with irregular waves, the biggest sand level change occurred in Test 11 (Hs $11.2 \mathrm{~cm}$ and Tp of 2.2 seconds) for model without gap (0D). While the test models with 1 diameter of gap, the biggest sand level change observed on Test 14 (Hs $10.7 \mathrm{~cm}$ and Tp 2 seconds). It is observed that the sand level changes mostly occurred at the rear of the structure. Several places at the rear and front of the structure experiencing sedimentation. In Test 14 where the gap is introduced, several locations on the front and rear structures also experiencing sedimentation, such as on the left front and the rear right of the structure. At the center of the structure (gap area), sedimentation only occurs on the right side of the structure, while on the left side of the structure scouring sand were observed.

Based on the regular and irregular test results above, the maximum scouring occurs on regular wave test. This is due to the amount of wave energy received by the sand layer is constant in regular waves, while in irregular wave, the energy fluctuates following the incoming waves.

\subsection{Maximum Scouring Analysis}

The maximum scouring depth (Sm) will be observed in this study. The maximum scouring depth is the maximum depth of sand level in the front and back of the Hexareef model after being tested in the wave tank for 60 minutes with an interval of recording per 5 minutes [7]. The maximum scouring depth (Sm), in the test without gap (0D)were in the range of $5 \mathrm{~cm}$ to $2.9 \mathrm{~cm}$. For the test with gap distance 1D, range of 
maximum scouring depth were $5.3 \mathrm{~cm}$ to $3 \mathrm{~cm}$. Table 3 below shows the maximum scouring depth recorded during experiment.

Table 3. Record of Maximum Scouring Depth for Each Test

\begin{tabular}{|c|c|c|c|c|c|c|}
\hline \multirow[t]{2}{*}{ Wave type } & \multirow[t]{2}{*}{ Gap } & \multirow{2}{*}{$\begin{array}{c}\mathbf{H i} \\
{[\mathbf{c m}]}\end{array}$} & \multirow{2}{*}{$\begin{array}{c}\mathbf{T i} \\
{[\mathbf{s e c}]}\end{array}$} & \multicolumn{2}{|c|}{$\begin{array}{c}\text { Scouring } \\
\text { depth }[\mathrm{cm}]\end{array}$} & \multirow{2}{*}{$\begin{array}{c}\mathbf{W} \\
{[\mathrm{cm}]}\end{array}$} \\
\hline & & & & Front & Rear & \\
\hline \multirow{8}{*}{ Regular } & \multirow{4}{*}{$0 \mathrm{D}$} & 8,3 & 2,0 & 2,9 & 3,7 & 37 \\
\hline & & 17,2 & 2,0 & 3,8 & 3,9 & 37 \\
\hline & & 11,4 & 4,0 & 4,4 & 4,2 & 37 \\
\hline & & 17,3 & 4,0 & 5,0 & 4,4 & 37 \\
\hline & \multirow{4}{*}{$1 \mathrm{D}$} & 9,7 & 2,0 & 3,5 & 4,0 & 30,83 \\
\hline & & 19,5 & 2,0 & 4,3 & 4,0 & 30,83 \\
\hline & & 11,3 & 4,0 & 4,1 & 4,3 & 30,83 \\
\hline & & 18,2 & 4,0 & 4,2 & 5,3 & 30,83 \\
\hline \multirow{6}{*}{$\begin{array}{c}\text { Irregular } \\
\text { (JONSWAP) }\end{array}$} & \multirow{3}{*}{$0 \mathrm{D}$} & 6,1 & 2,2 & 3,6 & 3,5 & 37 \\
\hline & & 9,0 & 2,2 & 3,9 & 3,4 & 37 \\
\hline & & 11,2 & 2,2 & 4,0 & 3,6 & 37 \\
\hline & \multirow{3}{*}{$1 \mathrm{D}$} & 6,0 & 1,9 & 3,0 & 3,0 & 30,83 \\
\hline & & 8,9 & 2,1 & 3,3 & 3,1 & 30,83 \\
\hline & & 10,7 & 2,0 & 3,6 & 3,1 & 30,83 \\
\hline
\end{tabular}

In the Table 3 above, $\mathrm{W}$ is the effective width of the structure, and can be calculated using following expression

$$
W=n A-(B / C) A
$$

where $\mathrm{n}$ is the number of Hexareef model, the width of $\mathrm{A}, \mathrm{B}$ and $\mathrm{C}$ as explain in Figure 3 below.

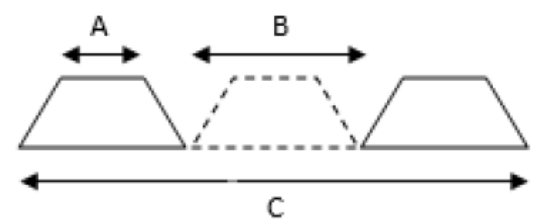

Fig. 3. Model Width Definition

The influence of wave height and period to maximum scouring depth $(\mathrm{Sm})$ in the front and rear of model were shown in figure 4 below.

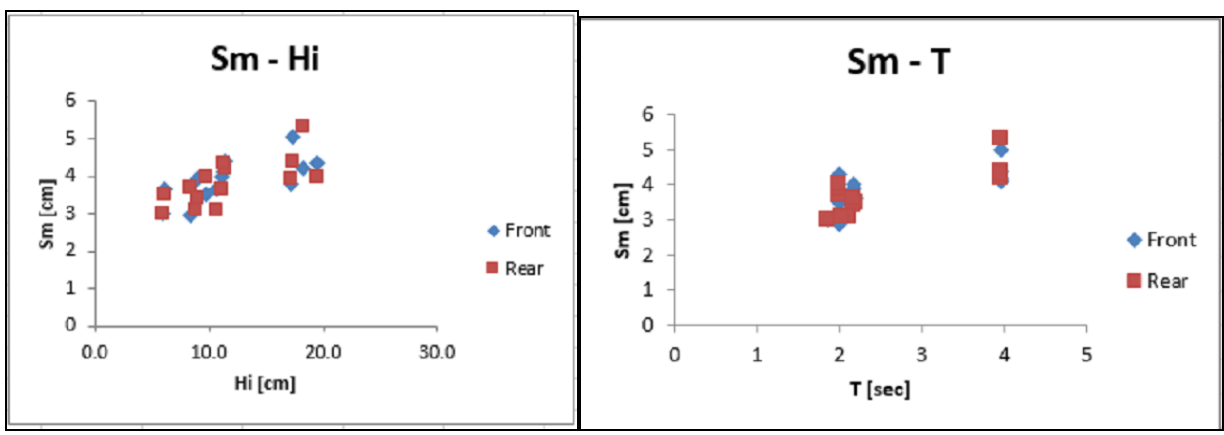

Fig. 4.The influence of wave height (Hi and wave period (T) to maximum scouring depth (Sm) 
It isobserved that the greater the value of incoming waves height and period, the greater the maximum scouring depth occurred in the front and rear of the structure. Other variables also influence the maximum scour depth, such as effective width (W) and water depth (h) as shown in Figure 5 below.

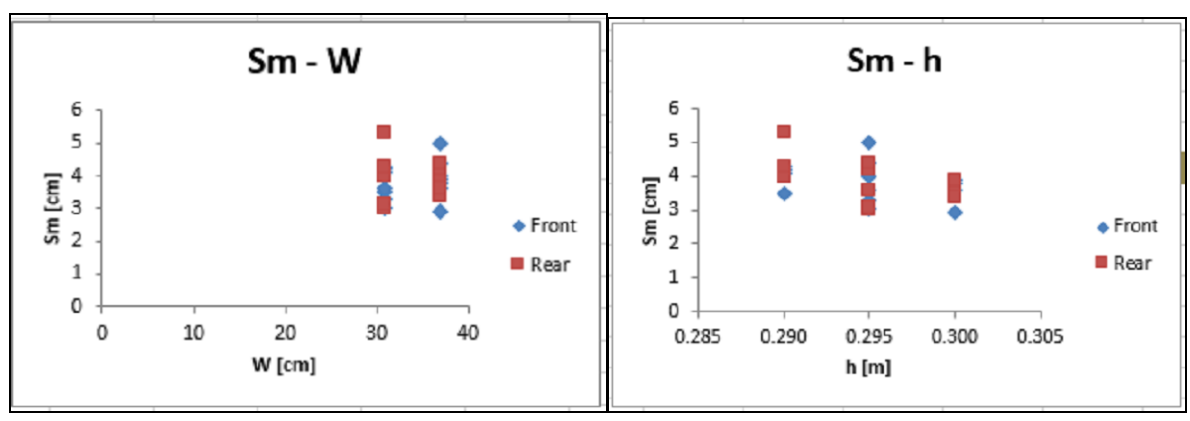

Fig.5.The influence of effective width (W) and water depth (h) to maximum scouring depth (Sm).

The smaller the effective width of the structure, the greater the scouring that occurs at the front and rear of the structure. The shallower the depth of water in an experiment, the greater the scouring that occurs at the front and rear of the structure.The influence of incoming wave height and period, effective width, water depth and other variables to maximum depth of scouring can be expressed as following equation:

$$
S_{m}=f(W, H i, T, h, d 50, \rho, \rho s, g)
$$

with,

$\mathrm{S}_{\mathrm{m}} \quad=$ maximum scouring depth $[\mathrm{m}]$

$\mathrm{W}=$ effective width of structure [m]

$\mathrm{H}_{\mathrm{i}} \quad$ = incident wave height [m]

$\mathrm{T} \quad=$ incident wave period [second]

$\mathrm{h} \quad=$ water depth [m]

$\mathrm{d}_{50}=$ sediment mean diameter $[\mathrm{m}]$

$\mathrm{g}=$ gravity acceleration $\left[\mathrm{m} / \mathrm{s}^{2}\right]$

$\rho \quad=$ water density $\left[\mathrm{Kg} / \mathrm{m}^{3}\right]$

$\rho_{s} \quad=$ sediment density $\left[\mathrm{Kg} / \mathrm{m}^{3}\right]$

By dimensional analysis, several dimensionless parameterscan be defined from equation 1 above and expresses as follows:

$$
S m / W=f\left(H i / W, h / W, d_{50} / W, \rho_{s} / \rho, g T^{2} / W\right)
$$

after compounding, equation (3) can be expressed as

$$
S_{m} / W=f\left(H i / W, h / W, d_{50} / W, \rho_{s} / \rho,(H i / T)^{2} /(g h)\right)
$$

Dimensionless parameter that is used to analyze the characteristics of scouring on submerged breakwater is Keulegan-Carpenter number and parameter number seabed mobility [9].

$$
K C=H_{i} / W
$$




$$
\Psi=\left(H_{i} / T \sinh (k h)\right)^{2} /\left(g^{*} h\right)
$$

By componding, those two dimensionless parametersabove can be developed from dimensionless parameters in Equation 3, making it suitable for use in the analysis of the characteristics of scouring. The main parameters of non-dimensional relationship between the depth of maximum scouring and the effective width of the structure $(\mathrm{Sm} / \mathrm{W})$ is influenced by variables making up the parameters of non-dimensional Keulegan-Carpenter (KC) by the square root of the parameter non-dimensional mobility number $(\Psi)$, which form the non-dimensionalparameter $\mathrm{KC} \Psi^{0.5}$ [9]

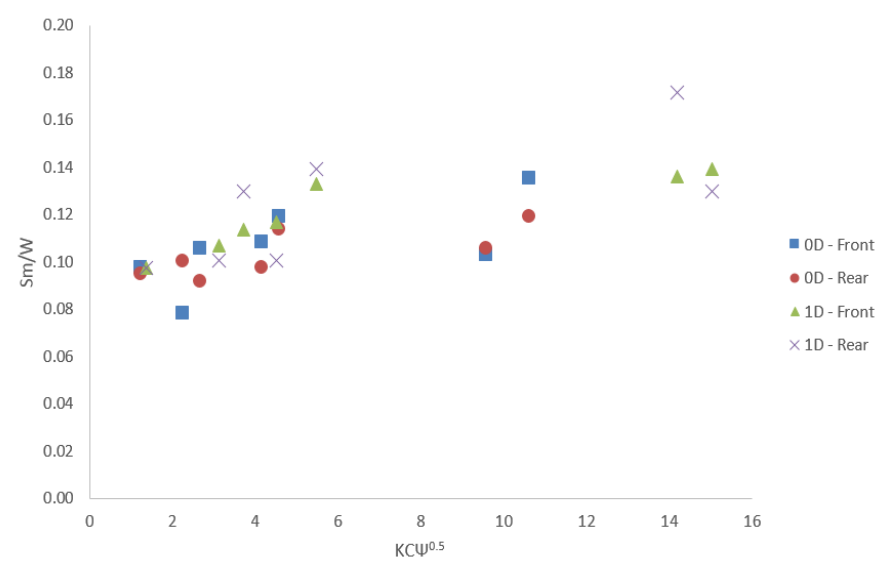

Fig. 6. Influence of $\mathrm{KC}$ number to maximum scour depth

Furthermore, following [2], a non-dimensionless parameter $\mathrm{KC} \Psi^{0.5}$ were plotted againts ratio of maximum scouring depth to effective width as shown in Figure 6 above. Some note about the distribution of the maximum scouring depth can be observed in Figure 6, including:

1. The maximum scouring occurs in the location behind the model for experiment with 1D gap

2. The minimum value for the overall testing of scouring depth occurred in front of the structure for OD gap.

3. In general, the maximum scouring occurs at $1 \mathrm{D}$ gap and the minimum at $0 \mathrm{D}$ gap

The maximum scouring depth for the front and rear structures can be estimated with an empirical equation developed by regression analysis [10] of the measured maximum scouring depth data obtained during the test. The empirical equations for the front and rear of Hexareef model expressed in equations 6 and 7 as follow.

$$
\begin{aligned}
& S_{m} / W_{b w}=0,0029\left(\psi^{0,5} K C\right)+0.0963 \\
& S_{m} / W_{b w}=0,0035\left(\psi^{0,5} K C\right)+0.0933
\end{aligned}
$$

From the results of the regression analysis above, (6) and (7) has a regression coefficient $\left(\mathrm{R}^{2}\right) \quad 0.5713$ and 0.4965 . It shows that only $57.13 \%$ and $49.65 \%$ of independent variables $\left(\mathrm{KC} \Psi^{0.5}\right)$ had correlation to the dependent variable $(\mathrm{Sm} / \mathrm{W})$. 
Several studies have been conducted on scouring evaluation around submerged breakwater such as [7] and [9], and empirical equations has been proposed from the study [9]

$$
S_{m} / W_{b w}=0,0125\left(\psi^{0,5} \mathrm{KC}\right)
$$

Figure 7 below is a comparison of the value of the maximum scouring depth on the rear of the structure of the research done by [7] and [9].

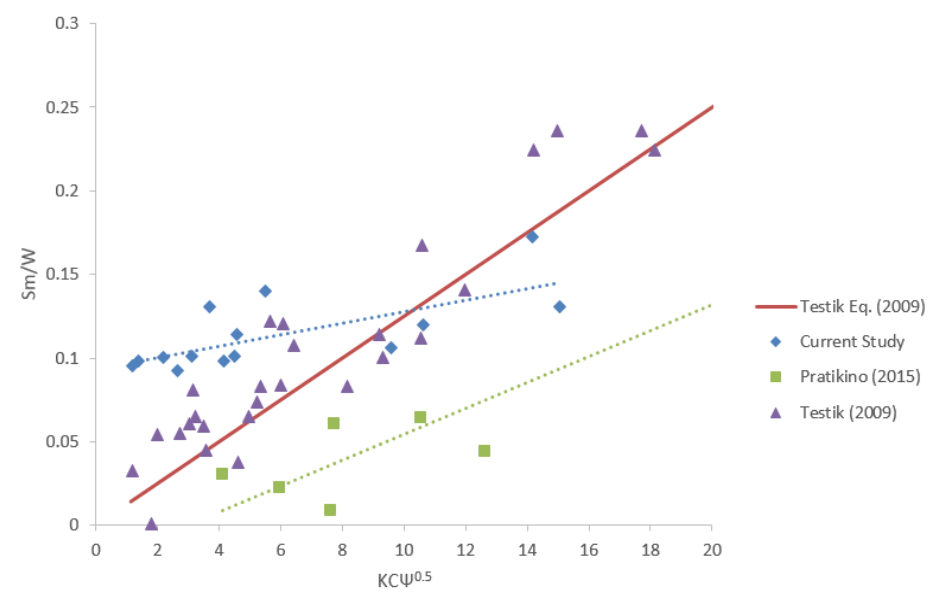

Fig. 7. Comparison withother Studies

The maximum scouring depth in this study has the increasing trend compared with other studies, which is the greater the value incoming wave height (Hi), the greater the depth of scouring. In this study, the scouring depth had a bigger value for the same wave height $\mathrm{Hi}$ and $\mathrm{KC}$ number compared to the research conducted by [7] and [9].

However, at certain value of $\mathrm{KC}$ number, the value of the maximum scouring depth in this study is smaller than research by [2] but larger than the research by [7]. Factor geometry of the structure, the depth of the waters of the test area, and the diameter of the granules also affects the maximum scouring depth. Geometry factors affect the rate of current flow formed around a structure, this will lead the scouring processes.

\section{Conclusion}

The following conclusion can be drawn from the study on the characteristics of scouring around Hexareef:

1. The higher of wave height and period resulted in the deeper scour that occurs around the Hexareef. The maximum scouring depth occurred in the range of $5.3 \mathrm{~cm}$ to $2.9 \mathrm{~cm}$. The maximum occurs on the test using regular waves.

2. The smaller the gap structure, the smaller scouring that occurs, while the larger the gap, the greater the scouring that occurs.

3. Anempirical equation for maximum scour estimation in front and rear of the structure has been proposed based simple linear regression analysis,using nondimensional parameter ( $\mathrm{Sm} / \mathrm{W}$ and $\left.\mathrm{KC} \Psi^{0.5}\right)$. 


\section{References}

1. H.D. Armono, Artificial Reef as Shoreline Protection Structures. ProsidingSeminar Teori dan Aplikasi Teknologi Kelautan IV. Surabaya, (2004).

2. B. M. Sumer, et al, Local Scour at Roundhead and Along the Trunk of Low Crested Structures, Coastal Engineering52 (2005) 995-1025

3. Carstensen, Stefan dan B. M. Sumer, Scour at Breakwaters Under Combined Waves and Current. E-proceddings of the 36th IAHR World Congress, The Hague. Netherlands, (2015).

4. S.A., Hughes, Scour and Scour Protection. CDCM Training Workshop Chapter 8. Trinidad, (2001).

5. R. Whitehouse, Scour at Marine Structures: A Manual for Practical Applications. Thomas Telford. UK, (1998).

6. J. Fredsoe and M.B. Sumer, The Mechanics of Scour in the Marine Environment. World Scientific: Singapore, (2002).

7. A.G., Pratikino, Karakteristik Scour di Sekitar Artificial Reef Bentuk Silinder Berongga. Thesis ITS. Surabaya, (2015).

8. FvD, Brink. Influence of Liquefaction on Scour around Offshore Monopile Foundations. Msc Thesis, University of Twente and Delft University of Technology. Netherlands. (2014).

9. D.M. Young and F.Y. Testik, Onshore Scour Characteristic around Submerged Vertical and Semicircular Breakwaters, Coastal Engineeering. 56 (2009) 868-875.

10. Harinaldi. Prinsip-Prinsip Statistik untuk Teknik dan Sains. Erlangga: Jakarta, (2005). 